\title{
Toward a Chatbot for Financial Sustainability
}

\author{
Sewoong Hwang ${ }^{1}$ and Jonghyuk Kim ${ }^{2, *}$ (i) \\ 1 Graduate School of Information, Yonsei University, 50, Yonsei-ro, Seodaemun-gu, Seoul 03722, Korea; \\ indimoa@gmail.com \\ 2 Division of Computer Science and Engineering, Sunmoon University, 70, Sunmoon-ro221beon-gil, \\ Tangjeong-myeon, Asan-si, Chungcheongnam-do 31460, Korea \\ * Correspondence: jonghyuk@sunmoon.ac.kr; Tel.: +82-41-530-2266
}

check for

updates

Citation: Hwang, S.; Kim, J. Toward a Chatbot for Financial Sustainability. Sustainability 2021, 13, 3173.

https://doi.org/10.3390/su13063173

Academic Editor: Salvador

Cruz Rambaud

Received: 17 February 2021

Accepted: 11 March 2021

Published: 13 March 2021

Publisher's Note: MDPI stays neutral with regard to jurisdictional claims in published maps and institutional affiliations.

Copyright: (c) 2021 by the authors. Licensee MDPI, Basel, Switzerland. This article is an open access article distributed under the terms and conditions of the Creative Commons Attribution (CC BY) license (https:// creativecommons.org/licenses/by/ $4.0 /)$.

\begin{abstract}
This study examines technology effectiveness for industry demand in which artificial intelligence (AI) is applied in the financial sector. It summarizes prior studies on chatbot and customer service and investigates theories on acceptance attitudes for innovative technologies. By setting variables, the study examines bank revenue methodologically and assesses the impact of customer service and chatbot on bank revenues through customer age classification. The results indicate that new product-oriented funds or housing subscription savings are more suitable for purchase through customer service than through chatbot. However, services for existing products through chatbot positively affect banks' net income. When classified by age, purchases by the majority age group in the channel positively affect bank profits. Finally, there is a tendency to process small banking transactions through the chatbot system, which saves transaction and management costs, positively affecting profits. Through empirical analysis, we first examine the effect of an AI-based chatbot system implemented to strengthen financial soundness and suggest policy alternatives. Second, we use banking data to increase the study's real-life applicability and prove that problems in customer service can be solved through a chatbot system. Finally, we investigate how resistance to technology can be reduced and efficiently accommodated.
\end{abstract}

Keywords: chatbot; artificial intelligence; financial sustainability; telemarketing; cube model; voice recognition and conversion model

\section{Introduction}

Professor Yoshua Bengio, the winner of the 2019 Turing Award, gave a lecture on core technologies in deep learning, such as meta-learning and reinforcement learning, at the Samsung AI Forum 2020 in November 2020. He refuted what Professor Carl Benedict Frey had argued, citing success stories in the application of information technology (IT) in the financial sector. Professor Frey had argued that less than half of financial jobs were set to disappear with the increasing use of artificial intelligence (AI). However, Professor Bengio predicted, Professor Frey's arguments would lose their convincing power [1], as it had happened for Professor Zoonky Lee who had published articles in a Korean newspaper to combat prejudice against artificial intelligence (Special Series of JoongAng Daily, "Lee Zoonky, Ask about the Future") [2]. The common points between Lee and Frey are as follows. Considering the history of technology adoption, technological innovation should be considered as a digital transformation that changes roles rather than kills jobs. Hence, as AI grows, digital transformation occurs and people seek new roles. A chatbot, which provides advice on financial products to customers, applies AI to the financial industry. Both Lee and Frey conclude that a chatbot does not eliminate jobs; rather, humans use the chatbot system to venture into new areas. The lack of insight, imagination, and responsiveness to new variables of the chatbot algorithms require humans to resolve them. Thus, AI creates a new ecosystem within the industry, and the role of humans changes for a new era in which machines and humans coexist in a complementary way [3]. 
Natural language processing technology and speech recognition technology are currently providing personal assistant services that communicate directly through personal mobile devices [4]. Chatbot, an interactive AI, has been widely deployed in finance, retail, public, and manufacturing industries. Apple's Siri, Amazon's Alexa, Google's OKgoogle, and Samsung Electronics' Bixby are good examples of voice conversion personal assistant services. In addition, Naver and Nugu of SK Telecom provide high-quality voice recognition services through the Korean search platform and communication market. As such, major IT companies, portal sites, and telecommunication companies worldwide are developing commercial voice recognition services and investing significant financial resources to provide AI services with higher accuracy [5].

This study investigates the role of $\mathrm{AI}$ in the financial industry from several aspects. First, the social demand for and expectations from artificial intelligence in the financial sector are high. The amount of investment in this field is larger compared to other industries such as the distribution, manufacturing, and public sectors [6]. Second, despite this interest, there are many misconceptions around using AI, and whether AI has been properly applied to the financial industry has been questioned [7]. Finally, the systematic criticism of AI technology applied to financial products is lacking in extant research. Recent media comments about AI describe the positive and negative effects of $\mathrm{AI}$ in a stimulating tone [8]. However, it is difficult to find an in-depth comparative study. Many recent studies examine the combination of $\mathrm{AI}$ and the financial sector because anyone who engages in economic activities is a financial consumer. Furthermore, even software used exclusively by traditional asset managers can be downloaded easily and used by ordinary people [9]. Hence, AI in the financial industry is simply a tool that individuals can access and use; it is not the exclusive property of experts. This study compares and analyzes the impact of customer service through the existing automatic response service (ARS) with the chatbot system currently being used by banks. In addition, we empirically analyze data to determine how each of these two channels (customer service and chatbot) affects bank profits and then derive practical implications based on the results [10].

The article structure is as follows. Section 2 reviews prior extant research, divided into four areas. First, through the latest research on financial chatbot systems, we investigate AI technologies and their effects in financial environments. Second, we summarize the research on problems faced by customer service counseling staff and on coping strategies and techniques to solve them. Third, we study theories of effective ways to introduce technology. Finally, we examine prior research on indicators representing bank contribution from a methodological perspective. In Section 3, we set the hypothesis for this study and perform statistical analysis based on bank data for new products and existing services by channel. We conduct quantitative analysis using statistical techniques to establish and verify the hypotheses while considering prior studies and descriptive statistics. Section 4 evaluates the theoretical underpinnings verified by data and summarizes the study. Finally, we conclude this study by revealing implications, limitations, and future research plans.

\section{Background}

\subsection{Financial Chatbot Service}

The term "chatbot" is a combination of "chatting" and "robot," which is commonly used for text messages or messengers. A chatbot is a communication software that can store appropriate answers to questions on a server, create models that continuously develop correct answers through conversations with customers, control exceptions, and provide accurate answers [11]. Chatbots create a self-learning model through computer programs and mathematical calculations and provide customers with answers and other relevant information as close as possible to user questions in real time. For companies, a chatbot is an interface that provides information required by customers and marketing through communication with financial consumers [12]. The first chatbot service in the financial sector was Bank of America's Erica introduced in May 2017. Erica's early look was similar to Apple's Siri. Erica provided simple text and voice-based responses, including trans- 
action details, limit amount, and account balance. Additionally, it provided advanced services such as credit rating upgrade application, fund product introduction, bank loan application, interest rate guidance, utility bill payment, and fund management consulting services $[13,14]$. The chatbot learned customers' personal profile information, past financial product purchase history, location information, and personal routine data by applying machine learning and deep learning technologies to provide accurate and customized services. Customers could enjoy convenience by securing personalized financial services quickly and easily through a chatbot [15]. In Korea, most commercial banks and other types of financial institutions have introduced chatbot services for customers (Table 1).

Table 1. Financial chatbot services in Korea.

\begin{tabular}{|c|c|c|c|c|}
\hline Type & $\begin{array}{c}\text { Financial } \\
\text { Institution }\end{array}$ & $\begin{array}{c}\text { Chatbot } \\
\text { Name }\end{array}$ & $\begin{array}{c}\text { Service } \\
\text { Platform }\end{array}$ & $\begin{array}{c}\text { Starting } \\
\text { from }\end{array}$ \\
\hline \multirow{5}{*}{$\begin{array}{c}\text { Banking } \\
\text { Corps. }\end{array}$} & Shinhan & Aurora & Shinhan Sol & 2018. 02 \\
\hline & Kookmin & Smartly (TalkTalk) & Liiv TalkTalk & 2017. 07 \\
\hline & $\mathrm{NH}$ & Consultation Talk & NH banking & 2018. 11 \\
\hline & Hana & HAI & Hana Members & 2017. 09 \\
\hline & Woori & Wibee-bot & WibeeTalk & 2018. 09 \\
\hline \multirow{4}{*}{$\begin{array}{l}\text { Credit } \\
\text { Card } \\
\text { Company }\end{array}$} & Shinhan & FANi & Shinhan Paypal & 2017. 06 \\
\hline & Samsung & Sam & Chatbot Sam & 2019. 03 \\
\hline & Hyundai & Henry \& Fiona & Buddy & 2017. 08 \\
\hline & Lotte & LOCA & The Loca Lab & 2018. 04 \\
\hline \multirow{5}{*}{$\begin{array}{c}\text { Others } \\
\text { (Securities, Insurance, and } \\
\text { Third Bank Sector) }\end{array}$} & Daishin (Sec.) & Benjamin & Kakao Talk & 2017. 09 \\
\hline & Samsung (Ins.) & Tabot & TABOT & 2017. 06 \\
\hline & Welcome (3rd S.) & Welcomebot & Kakao Talk & 2017. 09 \\
\hline & OK (3rd S.) & Oktok & Kakao Talk & 2017. 08 \\
\hline & JT (3rd S.) & JT Mobile Chatbot & Kakao Talk & 2018. 05 \\
\hline
\end{tabular}

Chatbots can be classified into a retrieval model and a generative model according to the implementation method in web or mobile applications. First, a chatbot based on the retrieval model is a rule-based method that provides prepared answers according to conditions of a specific topic or question. Most early chatbot versions in financial institutions were developed based on rules [16]. However, with the commercialization of chatbot, sophisticated machine learning has become possible as industry data continue to accumulate. Second, the generative model chatbot is a deep learning method that improves the accuracy of new responses through self-evolution as customer and communication data accumulate [17]. With the latest developments in deep learning technology, the system understands the customer's question and the intent of the sentence and presents the appropriate answer to the customer $[18,19]$. Therefore, it is possible to recommend personalized products for customers. Studies for commercialization are being actively conducted to capture current emotions of users through individual routines and basic profiles. Despite its many advantages, cost is an issue with the generative model because it requires the accumulation of vast amounts of data for continuous self-evolution [20].

Chatbots are important in terms of technology and user interface (UI). The chatbot is a technology service that implements communication between users and AI-based on text and voice and is a representative non-face-to-face service. Most chatbot services are implemented through conversational interactions based on customer questions and chatbot responses [21]. Through the interaction process with machines, customers perceive chatbots as objects of communication rather than simple machines [22]. Therefore, the chatbot service should be designed to reflect user needs and planned as an efficient and 
proven system with clear interactions. Chatbot services are mostly text-based messengers in online or mobile applications [23]. Therefore, a UI that enables customers to input and check information on a small screen effectively is essential. As shown in Table 2, design elements, such as product composition, button position, and background color, may vary depending on the screen. Therefore, the chatbot's design needs to project user experience on the screen elaborately. In addition, the screen of the chatbot is a publicity vehicle that presents the image of the company [24].

Table 2. Interface design elements of the financial chatbot.

\begin{tabular}{ccc}
\hline Process & Design Element & Interface Example \\
\hline \multirow{2}{*}{ Access Screen } & Functional Design & Chatbot location \\
\cline { 2 - 3 } & Value Design & Chatbot icon and name by function \\
\hline \multirow{2}{*}{ Start Screen } & Visual Design & Background color and overall layout \\
\cline { 2 - 3 } Answer Screen & Functional Design & Help on key features \\
\cline { 2 - 3 } & Functional Design & $\begin{array}{c}\text { Speech bubble space utilization and } \\
\text { option selection function }\end{array}$ \\
\hline Information Screen & Value Design & Character and profile image \\
\hline
\end{tabular}

\subsection{Telemarketing and Technical Elements of Alternative Systems}

Customer services centers provide online consultation with and for customers. They operate under various names such as customer support centers, call centers, contact centers, and customer relationship management (CRM) centers, depending on the company [25]. Initial customer service began as an organization that performed simple response services by receiving calls from customers [26]. In recent years, it has transformed into an organization that creates added value by enhancing the corporate image, providing information on products, conducting marketing and promoting activities, providing customer service, and communicating with customers. Customer service is an organization that provides non-face-to-face interactions with customers, but these interactions require emotional labor beyond face-to-face channels [27]. Customer service's emotional labor is an essential element of a company, as it can retain existing customers, attract new customers, and maintain a company's competitive advantage. However, this causes considerable stress on workers due to the incongruity of internal emotions and external expressions. These difficulties have led many companies to build systems that replace customer service [28,29].

Many technical elements are required to build an alternative customer service system. The customer service helper system must respond appropriately by inferring the meaning of the customer's question in real time [30]. For this reason, a semantic reasoning technique that can infer the meaning of a customer's query and provide an appropriate answer is essential. Semantic reasoning techniques can be classified into two broad categories according to their development process. First, knowledge-based question-and-answer (Q\&A) structures are used by humans in the system using an ontological method. This method finds the result by inferring the large-scale knowledge database built in a logical form. Second, information retrieval-based Q\&A orders a list of answers through probabilistic calculations by searching for answers to questions based on indexes in a large document set [31,32].

For the alternative customer service system to provide intelligent services, a Q\&A method through ontology-based reasoning should be used, rather than a simple rulebased search. Recently, owing to the development of deep learning technology, ontologybased Q\&A technology has been used in industries and chatbots in the financial sector (Table 3) [33]. Recently, the application of AI and advanced statistical analysis has enabled users to control local information, weather guidance, Internet searches, route searches, 
and product searches. These systems can provide advanced services based on user experiences [34].

Table 3. Components of intelligent virtual assistant technology.

\begin{tabular}{ccc}
\hline Division & Component \\
\hline Interactive interface & \multicolumn{2}{c}{ Speech recognition, multimodal, context recognition } \\
\hline \multirow{2}{*}{ Semantic reasoning } & Intelligence level & $\begin{array}{c}\text { Assistant chatbot, intelligent assistant, } \\
\text { cognitive assistant }\end{array}$ \\
\cline { 2 - 3 } & Conversation process & $\begin{array}{c}\text { Goal-oriented conversation processing, } \\
\text { question and answer skills }\end{array}$ \\
\cline { 2 - 3 } & Knowledge & Semantic Web, ontology-based technical data \\
\hline Other services & Modeling, big data analysis, web service \\
\hline
\end{tabular}

Another essential element for alternative customer service systems is voice recognition technology. In 1952, the AT\&T Bell Laboratory in the United States developed the first technology to convert recordings into text. Since then, various laboratories have attempted to develop speech recognition, but the accuracy has not exceeded $80 \%$. The low accuracy of voice recognition is due to different accents, volume, degree of dialect, and background noise [35].

Figure 1 illustrates a recently developed two-step voice recognition and conversion model that leverages deep learning techniques to recover ambiguous speech and further clarifies speech semantic transmission by considering speech characteristics and the surrounding environment. Voice recognition techniques are evolving into deep learning-based systems that can recognize speech, including long sentences or dialogues [36].

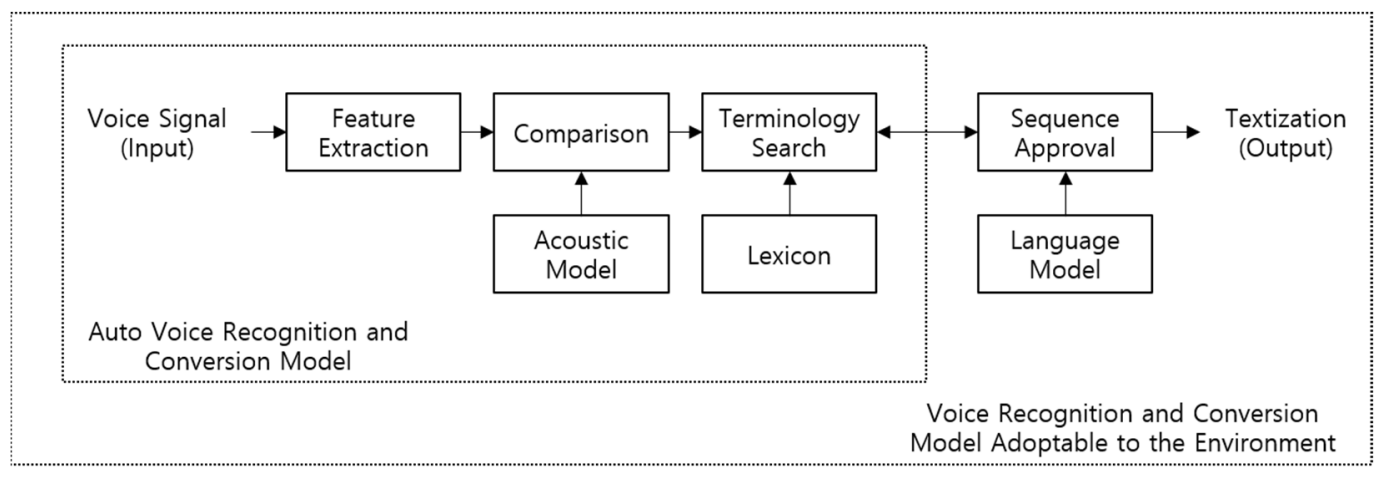

Figure 1. Two-step voice recognition and conversion model.

\subsection{Intention to Accept New Technology and Its Spread}

Due to internal conflicts and external situations of the system, it is difficult to accommodate and apply innovative technologies to existing systems to create a completely different paradigm [37]. In the financial sector, especially in organizations that perform customer services using mainly call centers, considerable conflicts, along with trial and error, will occur when applying chatbot services initially [10].

This study examines five theories on technology acceptance and diffusion. First, the theory of reasoned action (TRA) is the basis for acceptance and proliferation of new technologies, which argues that consumer attitudes influence behavior and that behavior can be predicted if attitudes are accurately measured. In particular, this theory presupposes that people are highly rational and systematically use the information they have. TRA has three components-attitude, subjective norm, and intention [38].

Second, the newly defined technology acceptance model (TAM) is based on TRA and focuses on user evaluation of the technology as a model to emphasize individual 
characteristics or beliefs in the process of accepting technology [39]. TAM argues that the greater the perceived ease and perceived helpfulness of users, the greater the behavior and intention of using technology. Used by several researchers, TAM is recognized as an excellent model that demonstrates simple and high explanatory power in explaining users IT acceptance and utilization behaviors [40].

Third, diffusion of innovation theory comprehensively describes the process by which a new paradigm of innovation is accepted and adopted by a particular organization or individual [41]. The theory considers the psychological rejection of accepting new techniques. Innovation resistance is the tendency of individuals to maintain their status quo. Created perceived risk is an important concept in accepting technologies. Perceived risk is the user's subjective perception of uncertainty about the future and possible negative consequences [42].

Fourth, the theory of planned behavior (TPB) is different from all of the above because it includes intentional action and strategic intention, and planned behavior control. This theory argues that control of intended and planned actions should be added to the performance of actions. TPB emphasizes that the main determinants of behavior are not the individual's attitude toward it but the intention to perform it and that it is under human control. From this perspective, we add a new concept, a critical variable called perceived behavior control, which sufficiently compensates for the weaknesses in rational behavior theory (Figure 2) [43].

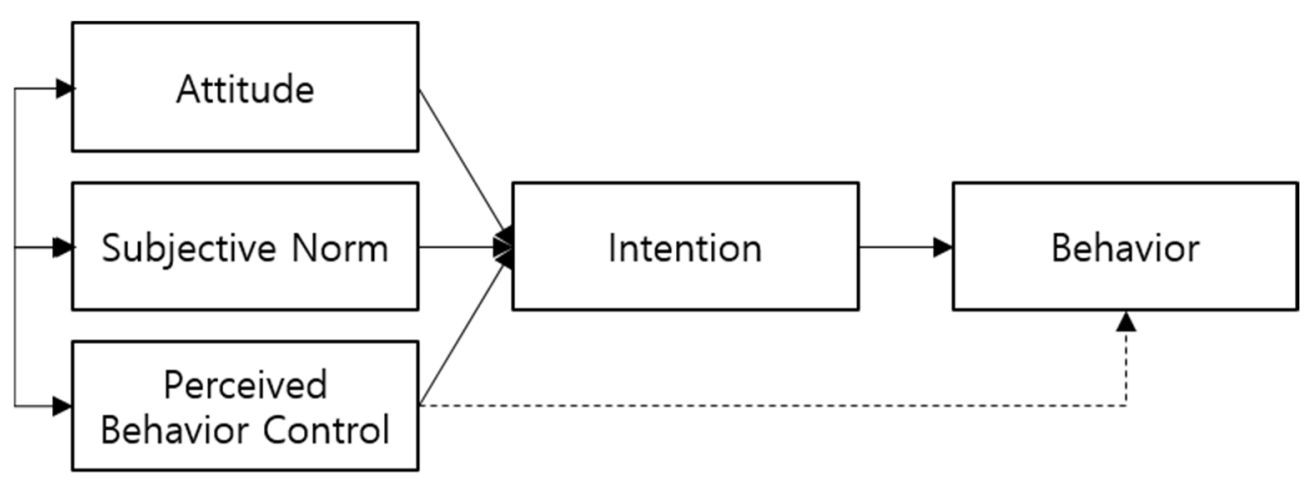

Figure 2. Schematic of the theory of planned behavior (TPB) model.

Fifth, the unified theory of acceptance and use of technology (UTAUT) is a highly descriptive model, because it has been selected as a significant proven factor through numerous trials and verification procedures [44]. In particular, studies analyzing acceptance of fintech payment services, by applying additional variables called reliability to UTAUT, show that individual effort, social impact, and reliability have a positive impact on the acceptance of fintech services. Furthermore, studies using UTAUT in consumer use of internet banking have shown that variables, such as information security risks, uncertainty risks, and transaction efficiency, have a negative impact on the dispersion of internet banking. Prior research results demonstrate that UTAUT is suitable for measuring the intent to use chatbot services introduced by many financial institutions. Studies have found that variables, such as consumer performance expectations, social impact, and promotion conditions, have a significant effect on bank performance [45].

Through the various technology acceptance models described above, we deduce a positive effect of lowering internal resistance and encouraging pro-sustainability behavior, even though there is the disadvantage of being slightly expensive strategically as several variables are added. In addition, we expect to be able to develop models for advancing theory improvement and environmental policy formulation [46]. 


\subsection{Profitability Indicators}

Research using detailed profitability indicator data from companies is limited. However, many studies in finance and accounting have used stock market data through the Open API (Application Programming Interface) as a dependent variable. Research has been conducted on the quality of services that are difficult to determine quantitatively [47]. In addition, there are many studies on how political factors cause instability in the financial industry. An empirical analysis of the Bank of Korea's profitability determinants and policy measures that conducted a regression analysis using independent variables such as equity ratio, per capita expenses, assets per capita, total receivable growth rate, and corporate bond yields [48]. A study of profitability determinants for commercial banks in Japan empirically analyzed how the classification of ownership structures affects profitability. The study used gross asset net profit margins, return on equity (ROE), and net interest margin (NIM) as indicators of profitability [49]. Furthermore, a Korean study conducted a multi-regression analysis using major financial indicators and macroeconomic data of general banks from 2000 to 2009 to identify the profitability determinants of banks. The study found that the non-profit loan ratio (NPL) had a statistically significant effect on the profitability of commercial and local banks, and that poor loan management in banks had a significant impact on asset size [50].

Research in the financial sector, which specializes in financial profitability, examined bank profitability determinants in Europe, North America, and Australia, using gross asset net return, return on capital (ROC), and value-added return on total assets as indicators of profitability [51]. Another study identified the impact of each independent variable on the subsidiary variable using gross capital operating profit, gross capital net income, gross capital net return, and net sales net income, of which gross asset net income was the most effective indicator [52]. Other studies compared the profitability and efficiency of commercial and local banks to examine the impact on the bank's management performance and suggested ways to stabilize the profitability of local banks. This was an empirical analysis of the factors affecting profitability with time-series cross-section regression, using portfolio mix as a methodology, and using changes in stock prices and gross capital return as an indicator [53]. In addition, long-term time-series data from 22 general banks were used to ascertain the determinants of the bank's management performance using the net return on assets and the ratio of non-profitable loans as an indicator of the general bank's profitability. These results demonstrate that macroeconomic variables affect bank asset portfolio and productivity variables. Another study used approximately 10 years of accounting data from Spain, Portugal, Germany, and France to analyze the relationship between net return on assets and net return on equity and profitability on commercial banks $[54,55]$.

\section{Methods}

\subsection{Samples and Data Collection}

This study analyzed product data from a large Korean banking company to determine the impact of customer product and service purchases on bank profits (return rate increase) based on two channels using ARS. We analyzed the statistical significance of how much each channel contributed to bank profits based on customer information using financial products and services through customer service calls or chatbot systems. We anticipate that our analysis will help banks derive measures to secure financial stability. Furthermore, we expect to empirically derive the extent to which AI-based chatbot can replace the existing customer service business for all financial affiliates, including banks. From Bank A, we collected 34,089 personal data of four major products and services sold through the chatbot channel for 36 months (on a daily basis) from January 2018 to December 2020, when the chatbot was first introduced at this bank. In addition, we collected 317,438 unstructured voice data acquired through customer service based on similar products at the same time. We standardized the unstructured data through a text conversion system and used a twostep voice recognition and conversion model. Except that each of the four products was 
handled through customer service or chatbot, all conditions were completely the same; therefore, it is safe to assume that the statistical effect is controllable in advance. Bank A is a nationwide commercial bank, with its target customers individuals residing in Korea; it handled all products during the time of the study. Therefore, the conditions for recognition of region, seasonality, environment, and age are the same. In addition, statistical sampling bias is assumed to be controlled, because the data handled were not part of the extracted data but the parameter data for the entire product. However, unlike chatbots, in the case of responses through counseling staff, there may be a promotional event depending on the period. Therefore, the purchase of a product different from the original purpose may occur due to a specific promotion. However, this cannot be measured quantitatively, and it can be assumed that the effect of counselor promotion is negligible in a situation in which the response to customer purchases is the primary purpose of inbound calls. We deleted sensitive information from Bank A's customer data through blur-masking. In addition, we made the response to the information protection request by performing mixed-combination conversion of the primary key and set it as data that can be analyzed through data cleansing. Financial product information as final analysis data is shown in Table 4.

Table 4. Classification of sample data.

\begin{tabular}{ccccc}
\hline Financial Goods & Customer Service & Chatbot & Total & \% \\
\hline Fund subscription & 28,435 & 2531 & 30,996 & 8.8 \\
Housing-subscription savings & 49,937 & 4365 & 54,302 & 15.4 \\
Loan interest payment & 54,833 & 6350 & 61,183 & 17.4 \\
Utility bill & 187,233 & 18,843 & 206,076 & 58.5 \\
Total & 320,438 & 32,089 & 352,527 & 100.0 \\
\hline
\end{tabular}

Bank A's main products are new sales of funds and home subscription savings products, loan interest payment and repayment services, and local taxes and utility expenses payment services, with a total of 351,527 cases. Since we used the analysis data based on the number of cases, we counted all duplicate product purchases. The data collected included contract channel (contract manager, chatbot unique allocation code), contract date and contract product, contractor's identification information, and contract number for the individual number of all products. Based on the data, we performed basic statistical information, data preprocessing, hypothesis setting, and testing. We used SAS University Edition, an open-source software, for statistical analysis and the Oracle virtual machine to prepare the software operating environment.

\subsection{Operational Definition and Preprocessing}

Information on the four financial products selected for this study and product information for each channel through offline counters and online ARS is summarized as follows. First, in the case of funds, the total assets of listed funds (ETFs) handled by six major Korean banking companies amounted to USD 50 billion at the end of 2019. Adding unlisted funds, the amount is over USD 100 billion, which is an increase of $26.1 \%$ year-on-year-this is classified into 335 domestic products and 115 overseas products. By investor entity, individual investors account for $38.6 \%$ and institutional and foreign investors, $61.4 \%$.

The second product group is housing subscription savings. As of August 2019, the number of Korean subscribers exceeded 25 million, accounting for $50 \%$ of the population, and the total amount exceeded USD 80 billion, with savings per person averaging at USD 3000.

The third product group is service products related to loan interest payment and repayment. At the end of 2019, the total amount of personal loans exceeded USD 1.3 trillion, including the amount on credit cards. The average loan per capita is USD 60,000, and interest expenses were, on average, over USD 300 per month.

The final product group, the amount paid in utility bills including local taxes and administrative fees is not large; however, recently commercial banks are promoting a 
policy to increase the number or amount through promotions. These policies have positive benefits for high interest rates and currency exchange; hence, consumers are also actively using this system. Table 5 shows the data preprocessing status.

Table 5. Data preprocessing according to variable classification.

\begin{tabular}{|c|c|c|}
\hline Variable & Preprocessing & Remarks \\
\hline Customer Number & $\begin{array}{l}\text { Assign a unique number after } \\
\text { masking }\end{array}$ & Excluding the first 2 digits \\
\hline Age & Age of subscribers & \\
\hline Age Group * & Age category of subscribers & $0=$ under and equal $45,1=$ over 45 \\
\hline Purchase Date * & Date of first contact & \\
\hline Approval Date & $\begin{array}{l}\text { Subscription savings, loan } \\
\text { payment, and utility bills are } \\
\text { processed in real time (same } \\
\text { with Purchase Date) }\end{array}$ & $\begin{array}{l}\text { Fund needs to adjust date } \\
\text { according to conditions }\end{array}$ \\
\hline Amount1 & Subscription amount of Funds & \\
\hline Amount2 & $\begin{array}{l}\text { Amount of } \\
\text { housing-subscription savings }\end{array}$ & \\
\hline Amount3 & $\begin{array}{l}\text { Amount of loan interest } \\
\text { payment }\end{array}$ & \\
\hline Amount4 & $\begin{array}{l}\text { Amount of utility bills } \\
\text { payment }\end{array}$ & $\begin{array}{l}\text { Includes national tax, local tax, and } \\
\text { other utility expenses }\end{array}$ \\
\hline Purchase Channel & $\begin{array}{l}\text { - Customer service: employee } \\
\text { \#- Chatbot: HQ unique code } \\
\text { (CB0-\#) }\end{array}$ & \\
\hline Channel Classification * & $\begin{array}{l}\text { Customer service and chatbot } \\
\text { channel classification }\end{array}$ & $0=$ customer service, $1=$ chatbot \\
\hline Net profit1 * & $\begin{array}{l}\text { Revenue from } \\
\text { Funds-Expenses }\end{array}$ & \multirow{4}{*}{$\begin{array}{l}\text {-Exp1: Counselor salary } \\
\text {-Exp2: Chatbot cost (develop and } \\
\text { maintenance)/average IT infra } \\
\text { depreciation period (daily-base) }\end{array}$} \\
\hline Net profit2 * & $\begin{array}{l}\text { Revenue from } \\
\text { housing-subscription } \\
\text { savings-Expenses }\end{array}$ & \\
\hline Net profit3 * & $\begin{array}{l}\text { Revenue from loan } \\
\text { interest-Expenses }\end{array}$ & \\
\hline Net profit4 * & $\begin{array}{l}\text { Revenue from utility } \\
\text { bills-Expenses }\end{array}$ & \\
\hline
\end{tabular}

* marked variable is newly created data for preprocessing.

As shown in Table 5, the * marked variable is newly created data for preprocessing. However, in the case of the fund's approval date, it may differ from the sale date depending on the product's contract terms and the buyer's credit terms. For this study, age groups were classified as "Junior" for individuals less than 45 years old, and "Senior" for individuals of 45 years and older. Purchasing channels were classified by the employee number-58 employees of the ARS team at the bank's head office-and the unique codes of employees of five other inbound marketing service companies. In the case of the chatbot, the purchasing channels were classified with Bank A's own chatbot allocation code starting with "СB00". All amount-related variables were calculated based on the total amount received by the bank for each product in the period. To estimate the effect of product-specific returns on bank contribution, we created a new variable of net increase or net income excluding costs from profits by using the gross return on assets (ROA), which was used as a dependent variable in previous studies. We set the customer service cost formula by dividing the number of customers by the sum of labor cost and organizational operation 
cost. We used the average annual depreciation cost ratio of general system infrastructure of $11.3 \%$ and general management cost for server operation to calculate the formula of development and operation cost for the chatbot. We divided this amount by the number of chatbot users and calculated the average cost per chatbot use. As a result, the final cost was set at USD 1.03 per case for customer service and USD 0.39 for the chatbot.

\subsection{Descriptive Analysis}

As shown in Table 6, in the specific classification of each channel-product group, among all consumers who purchased all financial products using ARS, the number of customers who purchased products through customer service was about 9.3 times more than those who purchased the same products through the chatbot. Therefore, $90.3 \%$ of the parameter data purchased products through customer service, whereas purchases through chatbot only remained at $9.7 \%$. In terms of age groups, the purchase of products and services through customer service is higher in the Senior group $(54.7 \%)$ than in the Junior group ( $45.3 \%$ ). This trend is the same for all four products sold through customer service. In particular, in the case of housing subscription savings, the gap widens by $14.6 \%$, which is approximately $5 \%$ more compared to the average of $9.5 \%$. In terms of the product purchase rate, $55.8 \%$ of customers use customer service to pay utility bills.

Table 6. Descriptive statistics.

\begin{tabular}{|c|c|c|c|c|c|c|c|}
\hline \multirow{2}{*}{ Channel } & \multirow{2}{*}{ Goods } & \multicolumn{4}{|c|}{ Age Groups } & \multirow{2}{*}{\multicolumn{2}{|c|}{ Total (\%) }} \\
\hline & & \multicolumn{2}{|c|}{ Junior (\%) } & \multicolumn{2}{|c|}{ Senior (\%) } & & \\
\hline \multirow{5}{*}{$\begin{array}{l}\text { Customer } \\
\text { Service }\end{array}$} & Fund & 15,665 & $(46.9)$ & 17,770 & (53.1) & 33,435 & (10.5) \\
\hline & H.S.S. & 23,469 & $(42.7)$ & 31,468 & (57.3) & 54,937 & (17.3) \\
\hline & L.I. & 22,845 & $(44.1)$ & 28,988 & (55.9) & 51,833 & (16.3) \\
\hline & Bills & 81,729 & (46.1) & 95,504 & (53.9) & 177,233 & $(55.8)$ \\
\hline & Total & 143,708 & $(45.3)$ & 173,730 & $(54.7)$ & 317,438 & \\
\hline \multirow{5}{*}{ Chatbot } & Fund & 2,023 & $(79.9)$ & 508 & $(20.1)$ & 2,531 & (7.4) \\
\hline & H.S.S. & 2,798 & (64.1) & 1,567 & (35.9) & 4,365 & $(12.8)$ \\
\hline & L.I. & 3,787 & (59.6) & 2,563 & $(40.4)$ & 6,350 & (18.6) \\
\hline & Bills & 13,105 & $(62.7)$ & 7,738 & $(37.1)$ & 20,843 & (61.1) \\
\hline & Total & 21,713 & $(63.7)$ & 12,376 & (36.3) & 34,089 & \\
\hline \multirow{5}{*}{ Total } & Fund & 17,688 & $(49.2)$ & 18,278 & $(50.8)$ & 35,966 & $(10.2)$ \\
\hline & H.S.S. & 26,267 & $(44.3)$ & 33,035 & (55.7) & 59,302 & (16.9) \\
\hline & L.I. & 26,632 & $(45.8)$ & 31,551 & $(54.2)$ & 58,183 & (16.6) \\
\hline & Bills & 94,834 & $(47.9)$ & 103,242 & $(52.1)$ & 198,076 & (56.3) \\
\hline & Total & 165,421 & (47.1) & 186,106 & (52.9) & 351,527 & \\
\hline
\end{tabular}

Regarding consumers using the chatbot, the distribution of purchases is completely different from that of customer service. First, in terms of frequency of use, the Junior group $(63.7 \%)$ clearly used the chatbot more than the Senior group (36.3\%). However, in terms of the product purchase rate, $61.1 \%$ of users, which is higher than customer service, used the chatbot for utility bill payment services. In addition, the frequency of purchases of funds and housing subscription savings, which are subscriptions for new products, is completely different from payment of loan interest or utility bills, which are services for existing products. The most striking statistic related to the difference between the chatbot and customer service channels is that customer service occupies a higher proportion of handling new products at $10.5 \%$ and $17.3 \%$, compared to $7.4 \%$ and $12.8 \%$ of the chatbot.

\subsection{Hypotheses}

Considering the statistics in the case of new product sales, the ratio of total purchases per channel was lower in chatbot than in customer service. Conversely, in terms of loan interest payment and utility bill management, the chatbot has a higher relative ratio than customer service. Based on these data, we posit the following hypothesis to fit the 
assumption of the null hypothesis that there is no basis for expecting that new product purchases through customer service will have a greater positive effect on bank profits than purchases through the chatbot:

Hypotheses 1 (H1). Comparing customer service and chatbot users, there is no difference in their impact on bank contribution according to product classification.

Considering age groups, the data demonstrated that the relative proportion of seniors is considerably large for products handled through customer service than for those handled through the chatbot. Conversely, in the case of product handling through chatbot, the proportion of Junior users was higher than that of Seniors. Therefore, we expect that specific age groups will have a greater positive effect on bank profits in the division by channel, and we propose the following hypothesis to fit into the null hypothesis assumption similar to $\mathrm{H} 1$ :

Hypotheses 2 (H2). Comparing customer service and chatbot users, there is no difference in their impact on bank contribution according to customer classification.

Finally, we examined the concrete effects of the two hypotheses. We created a cube model with a combination of four cases in the form of $2 \times 2$ by mixing product groups and customer age groups. We analyzed the effect of each combination on the increase or decrease in the bank's net income. We categorized the sale of funds and housingsubscription savings products as "new product sales," and categorized loan interest and payment of utility bills as "existing service provisions." Utilizing these categories and the two age groups, we developed the four areas as follows: (1) New product sales-Junior group, (2) Existing service provision-Junior group, (3) New product sales-Senior group, and (4) Existing service provision-Senior group. Table 7 presents the data of the cube combination.

Table 7. The relative ratio of rows and columns by cube combination.

\begin{tabular}{|c|c|c|c|c|c|c|}
\hline & \multirow[b]{2}{*}{ Combination } & \multicolumn{3}{|c|}{ Channel } & \multirow{2}{*}{$\begin{array}{c}\text { Col. } \\
\text { Ratio }\end{array}$} & \multirow{2}{*}{$\begin{array}{l}\text { Row } \\
\text { Ratio }\end{array}$} \\
\hline & & $\begin{array}{l}\text { Customer } \\
\text { Service }\end{array}$ & Chatbot & Total & & \\
\hline \multirow{3}{*}{ Junior } & New Products Sales & 39,134 & 4821 & 43,955 & 8.1 & 26.6 \\
\hline & Provision of Existing Services & 104,574 & 16,892 & 121,466 & 6.2 & 73.4 \\
\hline & Total & 143,708 & 21,713 & 165,421 & 6.6 & \\
\hline \multirow{3}{*}{ Senior } & New Products Sales & 49,238 & 2075 & 51,313 & 23.7 & 27.6 \\
\hline & Provision of Existing Services & 124,492 & 10,301 & 134,793 & 12.1 & 72.4 \\
\hline & Total & 173,730 & 12,376 & 186,106 & 14.0 & \\
\hline \multicolumn{2}{|r|}{ Total } & 317,438 & 34,089 & 351,527 & 9.3 & \\
\hline
\end{tabular}

We present the following hypotheses for each of the four combinations to investigate their bank contribution:

Hypotheses 3a (H3a). In the case of the Junior group who purchased new products, there was no difference in the degree of contribution to the bank according to the classification by channel;

Hypotheses $\mathbf{3 b} \mathbf{b} \mathbf{H} \mathbf{3} \mathbf{b})$. In the case of the Junior group that received the existing services, there was no difference in the degree of contribution to the bank according to the classification by channel;

Hypotheses 3c (H3c). In the case of the Senior group who purchased new products, there was no difference in the degree of contribution to the bank according to the classification by channel;

Hypotheses 3d (H3d). In the case of the Senior group that received the existing services, there was no difference in the degree of contribution to the bank according to the classification by channel. 


\section{Results}

\subsection{Statistical Hypothesis Testing}

To test Hypothesis 1, which assumes that there is no difference in the impact on bank contribution of customer service and chatbot users according to product classification, we performed an analysis of covariance (ANCOVA), as shown in Table 8.

Table 8. Covariance analysis test for Hypothesis 1 (H1).

\begin{tabular}{cccccc}
\hline & DF & SS & MS & F-Value & $p$-Value \\
\hline Model & 2 & 145.3548 & 72.6774 & 18.8893 & $<0.0001$ \\
Error & 357,435 & $1,375,248.4582$ & 3.8475 & & \\
Total & 357,437 & $1,375,393.8130$ & & & \\
\hline Parameter & DF & Estimate & S.E. & T for H & $p$-value \\
\hline Intercept & 1 & -1.4275 & 0.05251 & -2.719 & 0.0014 \\
T & 1 & 0.0215 & 0.1457 & 0.148 & $<0.0001$ \\
NT & 1 & 0.0378 & 0.2437 & 0.155 & $<0.0001$ \\
\hline
\end{tabular}

The results show that both purchases of new products and existing services have a significant effect on the increase or decrease in bank profits according to customer service and chatbot channels. This means that new product-oriented funds and housing subscription savings are more suitable for customer service than the chatbot. Conversely, services for existing products, such as loan interest or payment of utility bills, are more suitable for processing through chatbot, which has a positive effect on bank net income.

Hypothesis 2 assumes that there is no difference in the impact on bank contribution of customer service and chatbot users according to customer classification. We performed ANCOVA, as shown in Table 9, to test two or more elements, as in Hypothesis 1.

Table 9. Covariance analysis test for Hypothesis $2(\mathrm{H} 2)$.

\begin{tabular}{cccccc}
\hline & DF & SS & MS & F-Value & $p$-Value \\
\hline Model & 2 & 645.3548 & 322.6774 & 70.1013 & $<0.0001$ \\
Error & 357,435 & $1,645,278.4582$ & 4.6030 & & \\
Total & 357,437 & $1,645,923.8130$ & & & \\
\hline Parameter & DF & Estimate & S.E. & T for $\mathrm{H}_{0}$ & $p$-value \\
\hline Intercept & 1 & 3.4572 & 0.4251 & 8.133 & 0.073 \\
T & 1 & 0.0035 & 0.0024 & 1.458 & $<0.0001$ \\
NT & 1 & 0.0081 & 0.0075 & 1.080 & $<0.0001$ \\
\hline
\end{tabular}

Hypothesis 2 secured model suitability according to the F-test result $(\mathrm{F}=70.1013)$. From the results (Table 9), we conclude that both Junior and Senior customers have a significant effect on the increase or decrease of bank revenues according to the two customer channels-customer services and chatbot. In the case of product purchase through customer service, the proportion of Seniors was higher, while the proportion of Juniors was larger for the chatbot. In conclusion, the age group that occupies a relatively large proportion has a positive effect on bank profits.

The total number of samples in Hypothesis 3a is 43,955, which are Junior group customers purchasing new products. The dependent variable is the net increase in bank revenue. We tested the statistical significance of the difference according to the classification by channel.

In the case of Hypothesis 3a (Table 10), the assumption of equal variance is satisfied by the $\mathrm{F}$ test $(\mathrm{F}=8.12)$. Therefore, we refer to the pooled $\mathrm{t}$-test, and the test result accepts the hypothesis $(t=1.4352)$. Hence, when comparing customers who purchase products through customer service and customers who purchase products through chatbot, that there is no difference in the bank net profit (New products-Junior group). 
Table 10. Two-sample $t$-test for Hypothesis 3a (H3a).

\begin{tabular}{ccccc}
\hline & Variance & DF & t-Value & $p$-Value \\
\hline Pooled & Equal & 43,953 & 1.4352 & 0.312 \\
Satterthwaite & Unequal & $43,864.245$ & 1.4345 & 0.416 \\
Equality of Variance & Num DF & Den DF & F-value & $p$-value \\
Folded F & 39,134 & 4821 & 8.12 & 0.357 \\
\hline
\end{tabular}

Hypothesis $3 b$ is classified by product-customer, and the total number of samples is 121,466 users: Junior customers receiving existing services. The dependent variable is the net increase in revenue for the bank. We tested the statistical significance of differences in channel classification.

In the case of Hypothesis $3 b$ (Table 11), the assumption of equal variance is satisfied by the $\mathrm{F}$ test $(\mathrm{F}=6.19)$. Therefore, we referred to the pooled $\mathrm{t}$-test, and the test result rejected the hypothesis $(t=18.2142)$. That is, when comparing customers who purchase through customer service and those who purchase through chatbot, bank net profits from the customer groups (Existing service-Junior group) are statistically different. In the case of the Junior group receiving only existing service, the bank profit was higher from the chatbot group than from the customer service group. The junior group's handling of small amounts of multiple utility bills through the chatbot has a positive effect on bank finances due to the regular transaction costs of customer service. Therefore, inducing the use of chatbots with low operating costs is a positive contribution to the bank, due to the nature of existing services involving a small amount of money but a larger number of transactions.

Table 11. Two-sample $t$-test for Hypothesis $3 \mathrm{~b}$ (H3b).

\begin{tabular}{ccccc}
\hline & Variance & DF & t-Value & $p$-Value \\
\hline Pooled & Equal & 121,464 & 18.2142 & 0.012 \\
Satterthwaite & Unequal & $121,435.328$ & 14.2146 & 0.011 \\
Equality of Variance & Num DF & Den DF & F-value & $p$-value \\
Folded F & 104,574 & 16,892 & 6.19 & 0.452 \\
\hline
\end{tabular}

In Hypothesis 3c, the total number of samples classified by product and customer is 51,313 because they are customers who purchase new products and belong to the Senior group. The dependent variable is the net increase in bank revenue. We tested the statistical significance of differences in channel classification.

For Hypothesis 3c (Table 12), the assumption of equal variance was not satisfied by the $\mathrm{F}$ test $(\mathrm{F}=23.73)$. Therefore, we refer to the $t$-test of the Satterthwaite method, and the test result rejects the hypothesis $(t=34.1223)$. When comparing customers who purchase through customer service and those who purchase through chatbot, bank net profits of these group customers (New product purchase-Senior group) are not statistically equal. This result is due to the large number of Senior group customers who purchase new products such as funds and savings through customer service. Additionally, the amount of fund products is large. This increases the average bank receipts. In addition, since the housing subscription savings product has regularity, it is expected to have a positive role in terms of bank contribution.

Table 12. Two-sample $t$-test for Hypothesis 3c (H3c).

\begin{tabular}{ccccc}
\hline & Variance & DF & t-Value & $p$-Value \\
\hline Pooled & Equal & 51,311 & 21.0113 & $<0.0001$ \\
Satterthwaite & Unequal & $51,304.525$ & 34.1223 & $<0.0001$ \\
Equality of Variance & Num DF & Den DF & F-value & $p$-value \\
Folded F & 49,238 & 2075 & 23.73 & $<0.0001$ \\
\hline
\end{tabular}


In Hypothesis $3 \mathrm{~d}$, when categorized by product and customer, the total number of samples is 134,793; they are users receiving existing services and customers belonging to the Senior group by age. The dependent variable is the net increase in revenue for the bank. We tested the statistical significance of differences in channel classification.

In the case of Hypothesis 3d (Table 13), the assumption of equal variance is not satisfied by the $\mathrm{F}$ test $(\mathrm{F}=12.09)$. Therefore, we refer to the Satterthwaite method $\mathrm{t}$-test, and the test result rejects the hypothesis $(t=-12.1025)$. Contrary to Hypothesis $3 b$, in the case of the Senior group, handling existing services with high transaction frequency and small monetary amounts through customer services has high transaction costs and a negative effect on bank revenue.

Table 13. Two-sample $t$-test for Hypothesis $3 \mathrm{~d}(\mathrm{H} 3 \mathrm{~d})$.

\begin{tabular}{ccccc}
\hline & Variance & DF & t-Value & $p$-Value \\
\hline Pooled & Equal & 134,791 & -13.1452 & 0.026 \\
Satterthwaite & Unequal & $134,731.583$ & -12.1025 & 0.025 \\
Equality of Variance & Num DF & Den DF & F-value & $p$-value \\
Folded F & 124,492 & 10,301 & 12.09 & $<0.034$ \\
\hline
\end{tabular}

\subsection{Cube Model Interpretation}

To plot the results of Hypothesis 3, the combination of two conditions by product and by age was made into a $2 \times 2$ cube model. The $X$-axis is divided into the age group of customers, and the Y-axis is divided into product characteristics. In addition, we divided the channels into customer service and chatbot. We plotted the four combinations and analyzed the effect of each combination on bank revenue. The analysis results for each combination are shown in Table 14.

Table 14. Interpretation of the hypotheses from the cube model.

\begin{tabular}{ccc}
\hline $\begin{array}{c}\text { New Products } \\
\left(\mathrm{Y}_{1}\right)\end{array}$ & $\begin{array}{c}\mathrm{X}_{1}-\mathrm{Y}_{1}(\mathrm{H} 3 \mathrm{a}) \\
\text { Not significant }\end{array}$ & $\begin{array}{c}\mathrm{X}_{2}-\mathrm{Y}_{1}(\mathrm{H} 3 \mathrm{c}) \\
\text { Positive in net profit } \\
\text { from Customer Service }\end{array}$ \\
\hline $\begin{array}{c}\text { Existing Service } \\
\left(\mathrm{Y}_{2}\right)\end{array}$ & $\begin{array}{c}\mathrm{X}_{1}-\mathrm{Y}_{2}(\mathrm{H} 3 \mathrm{~b}) \\
\text { Negative in net profit } \\
\text { from Chatbot }\end{array}$ & $\begin{array}{c}\mathrm{X}_{2}-\mathrm{Y}_{2}(\mathrm{H} 3 \mathrm{~d}) \\
\text { Negative in net profit } \\
\text { from Customer Service }\end{array}$ \\
\hline & Junior Group \\
$\left(\mathrm{X}_{1}\right)$ & $\begin{array}{c}\text { Senior Group } \\
\left(\mathrm{X}_{2}\right)\end{array}$ \\
\hline
\end{tabular}

As for $\mathrm{X} 1-\mathrm{Y} 1$, the hypothesis of the study was adopted, so there is no difference in the effect on the net profit of banking operations between the two channels. In the case of X1$\mathrm{Y} 2$, the analysis result was significant, because multiple small transactions were able to save labor and management costs through automated processing. Additionally, X2-Y1 positively affected contribution based on the behavior of the Senior group purchasing new products with large amounts of money. Finally, in the case of X2-Y2, multiple micro-transactions using a chatbot rather than using customer service positively affect bank finances.

\section{Conclusions}

This study conducted an empirical analysis to pursue the expansion of the use of AI-enabled chatbot in banking financial products and bank policy changes, based on the ARS data of leading banks. For empirical analysis, we summarized the practical implications through the results of hypotheses setting and testing. First, we empirically analyzed the effect of the AI-based chatbot system and suggested policy alternatives to strengthen the financial soundness of large banks. We evaluated the performance of the chatbot system, newly introduced to the existing ARS system in January 2018. In addition, we presented alternatives on how this system contributed financially to banks 
and what aspects should be supplemented to optimize customized profits in the future. The findings indicate that reinforcing customer service expertise according to product and age classification increases bank profits. In some chatbot cases, the increase is greater. Second, companies, especially in the financial sector, are furiously building AI platforms. However, applying new technologies to the field, including acceptance and adaptations, requires considerable time and public relations, and may result in internal friction. This can affect short-term profits and may lead to economic opportunity losses. If companies fail to make the right investment at the right time, they may forfeit future opportunities. Therefore, this study categorized whether banks are investing with an eye to profits and analyzed the effectiveness of these investments. This study can be applicable to financial institutions other than banks in the future.

We examined previous studies in four dimensions and in that backdrop, summarize the academic contributions of this study. First, considering the financial chatbot system, we examined AI technologies and effects introduced in various financial environments through prior research. Second, in relation to the ARS system, we summarized the practical problems of customer service counseling staff and the countermeasures and techniques to solve them. Third, we studied the properties of resistance to the introduction of technologies and theories related to alternatives that help reduce the resistance and increase acceptance. Fourth, we investigated prior research on actual indicators representing bank contribution from a methodological perspective. Thus, this study provides a real-world situation through data and meaningful statistical inference.

Despite the various academic significances and practical contributions described above, there are problems and limitations of this study. First, data handled at offline counters that account for most product management were excluded. Banks sell bankspecific savings and loan products, and they offer specialized products such as insurance and bonds. The percentage of products sold through ARS is less than $5 \%$ of the bank's total sales. Of these, sales through chatbot are insignificant, less than $10 \%$; hence, it may be unreasonable to closely associate them with bank profits. However, building a new infrastructure for a chatbot is an important factor, considering the unknown impact for the new era. Therefore, continuous research on the introduction of the AI financial system is necessary. Second, the four products and services presented in this study are all parameters of the data accumulated for two years after the chatbot was introduced. These data were developed through trial and error at the time of initial settlement, and the stability of the sample is poor. In addition, there are many macro-environment variables that should be considered along with the impacts presented in this study. This is expected to be a problem that can be resolved naturally as data are continuously accumulated and the system is stabilized in the future. Nonetheless, it remains practically and academically necessary to continuously correct these problems for research. Third, we also need to design an experiment by separating the cases of failure from the success cases in the chatbot service and additionally analyze the service failure factors [56]. In other words, we need meticulous research to control situations that are unfamiliar to customers through further investigation of chatbot service failures. Fourth, we overlooked dealing with digital governance issues. The main challenge in digital governance is not technical but the people involved in the decision-making process [57]. In other words, it is important to create a governance structure so that people participate in decision making and at the same time do not fall into the trap of knowledge issues. Therefore, we need to provide multiple processes at different levels for a sustainable transition to digital governance. Finally, we omitted the study of distorted trust between social cognition and the cognitive ability of chatbots [58]. In other words, we need to list the significant negative impacts of a number of faulty interfaces that could be considered in the conceptual model of a chatbot and provide reasonable evidence of its impact on users. We expect that through the process of closing this set of limitations, we will be able to more accurately relocate the contributions of our research to the digitization of society through chatbots. 
Author Contributions: Data curation, S.H. and J.K.; formal analysis, S.H. and J.K.; funding acquisition, J.K.; methodology, S.H. and J.K.; project administration, J.K.; visualization, S.H.; writingoriginal draft preparation, S.H. and J.K.; writing-review and editing, J.K. All authors have read and agreed to the published version of the manuscript.

Funding: This research received no external funding.

Institutional Review Board Statement: Not applicable.

Informed Consent Statement: Not applicable.

Data Availability Statement: Not applicable.

Conflicts of Interest: The authors declare no conflict of interest.

\section{References}

1. Brundage, M.; Avin, S.; Wang, J.; Belfield, H.; Krueger, G.; Hadfield, G.; Khlaaf, H.; Yang, J.; Toner, H.; Fong, R. Toward trustworthy AI development: Mechanisms for supporting verifiable claims. arXiv 2020, arXiv:2004.07213.

2. Zoonky, L. Ask about the Future. JoongAng Ilbo, 25 January 2021. Available online: https://news.joins.com/article/23977466 (accessed on 25 January 2020).

3. Burström, T.; Parida, V.; Lahti, T.; Wincent, J. AI-enabled business-model innovation and transformation in industrial ecosystems: A framework, model and outline for further research. J. Bus. Res. 2021, 127, 85. [CrossRef]

4. Bender, E.M.; Friedman, B. Data statements for natural language processing: Toward mitigating system bias and enabling better science. Trans. Assoc. Comput. Linguist. 2018, 6, 587. [CrossRef]

5. Ha, J.-W.; Nam, K.; Kang, J.G.; Lee, S.-W.; Yang, S.; Jung, H.; Kim, E.; Kim, H.; Kim, S.; Kim, H.A. ClovaCall: Korean goal-oriented dialog speech corpus for automatic speech recognition of contact centers. arXiv, 2020; arXiv:2004.09367.

6. Okuda, T.; Shoda, S. AI-based chatbot service for financial industry. Fujitsu Sci. Tech. J. 2018, $54,4$.

7. Lin, T.C. Artificial Intelligence, Finance, and the Law. Fordham L. Rev. 2019, 88, 531.

8. Fadziso, T. Ethical Issues on Utilization of AI, Robotics and Automation Technologies. Asian J. Humanit. Art Lit. $2020,7,79$.

9. Malali, A.B.; Gopalakrishnan, S. Application of Artificial Intelligence and Its Powered Technologies in the Indian Banking and Financial Industry: An Overview. IOSR J. Humanit. Soc. Sci. 2020, 25, 55.

10. Przegalinska, A.; Ciechanowski, L.; Stroz, A.; Gloor, P.; Mazurek, G. In bot we trust: A new methodology of chatbot performance measures. Bus. Horiz. 2019, 62, 785-797. [CrossRef]

11. Serban, I.V.; Sankar, C.; Germain, M.; Zhang, S.; Lin, Z.; Subramanian, S.; Kim, T.; Pieper, M.; Chandar, S.; Ke, N.R. A deep reinforcement learning chatbot. arXiv, 2017; arXiv:1709.02349.

12. Yu, S.; Chen, Y.; Zaidi, H. A Financial Service Chatbot based on Deep Bidirectional Transformers. arXiv 2020, arXiv:2003.04987.

13. Moysan, Y.; Zeitoun, J. Chatbots as a lever to redefine customer experience in banking. J. Digit. Bank. $2019,3,242$.

14. Sharma, S.; Sharma, N.; Vyas, R. Artificial Intelligence: Legal Aspects, Risks: Are We Ready for Such Intelligent Autonomous Machines? Neoteric Multidiscip. Res. J. NR Res. Publ. 2018, 1, 1-12.

15. Kim, J.W.; Jo, H.I.; Lee, B.G. The Study on the Factors Influencing on the Behavioral Intention of Chatbot Service for the Financial Sector: Focusing on the UTAUT Model. J. Digit. Contents Soc. 2019, 20, 41. [CrossRef]

16. Tammewar, A.; Pamecha, M.; Jain, C.; Nagvenkar, A.; Modi, K. Production ready chatbots: Generate if not retrieve. arXiv, 2017; arXiv:1711.09684

17. Karri, S.P.R.; Kumar, B.S. Deep learning techniques for implementation of chatbots. In Proceedings of the International Conference on Computer Communication and Informatics (ICCCI), Da Nang, Vietnam, 30 November-3 December 2020; IEEE: Piscataway, NJ, USA, 2020; pp. 1-5.

18. Wu, W.; Yan, R. Deep chit-chat: Deep learning for chatbots. In Proceedings of the 42nd International ACM SIGIR Conference on Research and Development in Information Retrieval, Paris, France, 21-25 July 2019; pp. 1413-1414.

19. Karna, M.; Juliet, D.S.; Joy, R.C. Deep learning based Text Emotion Recognition for Chatbot applications. In Proceedings of the 4th International Conference on Trends in Electronics and Informatics (ICOEI)(48184), Tamilnadu, India, 16-18 April 2020; IEEE: Piscataway, NJ, USA, 2020; pp. 988-993.

20. Ukpabi, D.C.; Aslam, B.; Karjaluoto, H. Chatbot adoption in tourism services: A conceptual exploration. In Robots, Artificial Intelligence, and Service Automation in Travel, Tourism and Hospitality; Emerald Publishing Limited: Bingley, UK, 2019.

21. Handoyo, E.; Arfan, M.; Soetrisno, Y.A.A.; Somantri, M.; Sofwan, A.; Sinuraya, E.W. Ticketing chatbot service using serverless NLP technology. In Proceedings of the 5th International Conference on Information Technology, Computer, and Electrical Engineering (ICITACEE), Jakarta, Indonesia, 27-28 September 2018; IEEE: Piscataway, NJ, USA, 2018; pp. 325-330.

22. Ciechanowski, L.; Przegalinska, A.; Magnuski, M.; Gloor, P. In the shades of the uncanny valley: An experimental study of human-chatbot interaction. Future Gener. Comput. Syst. 2019, 92, 539-548. [CrossRef]

23. Jain, M.; Kumar, P.; Kota, R.; Patel, S.N. Evaluating and informing the design of chatbots. In Proceedings of the Designing Interactive Systems Conference, Hong Kong, China, 9-13 June 2018; pp. 895-906. 
24. Nguyen, T. Potential Effects of Chatbot Technology on Customer Support: A Case Study. Master's Thesis, Aalto University, Espoo, Finland, 2019.

25. Dewnarain, S.; Ramkissoon, H.; Mavondo, F. Social customer relationship management: An integrated conceptual framework. J. Hosp. Mark. Manag. 2019, 28, 172-188. [CrossRef]

26. Zerbino, P.; Aloini, D.; Dulmin, R.; Mininno, V. Big Data-enabled customer relationship management: A holistic approach. Inf. Process. Manag. 2018, 54, 818-846. [CrossRef]

27. Chi, N.W.; Wang, I.A. The relationship between newcomers' emotional labor and service performance: The moderating roles of service training and mentoring functions. Int. J. Hum. Resour. Manag. 2018, 29, 2729-2757. [CrossRef]

28. Grandey, A.A.; Melloy, R.C. The state of the heart: Emotional labor as emotion regulation reviewed and revised. J. Occup. Health Psychol. 2017, 22, 407. [CrossRef] [PubMed]

29. Cho, Y.J.; Song, H.J. Determinants of turnover intention of social workers: Effects of emotional labor and organizational trust. Public Pers. Manag. 2017, 46, 41-65. [CrossRef]

30. Adam, M.; Wessel, M.; Benlian, A. AI-based chatbots in customer service and their effects on user compliance. Electron. Mark. 2020, 1-19. [CrossRef]

31. Zhang, Y.; Zhang, M.; Luo, N.; Wang, Y.; Niu, T. Understanding the formation mechanism of high-quality knowledge in social question and answer communities: A knowledge co-creation perspective. Int. J. Inf. Manag. 2019, 48, 72-84. [CrossRef]

32. Garcia, N.; Otani, M.; Chu, C.; Nakashima, Y. KnowIT VQA: Answering knowledge-based questions about videos. In Proceedings of the AAAI Conference on Artificial Intelligence, New York, NY, USA, 7-12 February 2020; Volume 34, pp. 10826-10834.

33. Mohemad, R.; Noor, N.M.M.; Ali, N.H.; Li, E.Y. Ontology-Based Question Answering System in Restricted Domain. J. Telecommun. Electron. Comput. Eng. 2017, 9, 29-33.

34. Kumar, V.; Rajan, B.; Venkatesan, R.; Lecinski, J. Understanding the role of artificial intelligence in personalized engagement marketing. Calif. Manag. Rev. 2019, 61, 135-155. [CrossRef]

35. Singh, N. Automatic speaker recognition: Current approaches and progress in last six decades. Glob. J. Enterp. Inf. Syst. 2017, 9 , 45-52. [CrossRef] [PubMed]

36. Wang, H. Two-step Judgment Algorithm for Robust Voice Activity Detection Based on Deep Neural Networks. In Proceedings of the International Computers, Signals and Systems Conference (ICOMSSC), Dalian, China, 28-30 September 2018; IEEE: Piscataway, NJ, USA, 2018; pp. 84-86.

37. Perez, C. Structural change and assimilation of new technologies in the economic and social systems. Futures 1983, 15, 357-375. [CrossRef]

38. Pavlou, P.A. Consumer acceptance of electronic commerce: Integrating trust and risk with the technology acceptance model. Int. J. Electron. Commer. 2003, 7, 101-134.

39. Lee, Y.; Kozar, K.A.; Larsen, K.R. The technology acceptance model: Past, present, and future. Commun. Assoc. Inf. Syst. 2003, 12, 50. [CrossRef]

40. Chuttur, M.Y. Overview of the technology acceptance model: Origins, developments and future directions. Work. Pap. Inf. Syst. 2009, 9, 9-37.

41. Dearing, J.W. Applying diffusion of innovation theory to intervention development. Res. Soc. Work. Pract. 2009, 19, 503-518. [CrossRef] [PubMed]

42. Min, S.; So, K.K.F.; Jeong, M. Consumer adoption of the Uber mobile application: Insights from diffusion of innovation theory and technology acceptance model. J. Travel Tour. Mark. 2019, 36, 770-783. [CrossRef]

43. Ajzen, I. The theory of planned behavior: Frequently asked questions. Hum. Behav. Emerg. Technol. 2020, 2, 314-324. [CrossRef]

44. Im, I.; Hong, S.; Kang, M.S. An international comparison of technology adoption: Testing the UTAUT model. Inf. Manag. 2011, 48, 1-8. [CrossRef]

45. Williams, M.D.; Rana, N.P.; Dwivedi, Y.K. The unified theory of acceptance and use of technology (UTAUT): A literature review. J. Enterp. Inf. Manag. 2015, 28, 443-488. [CrossRef]

46. Steg, L.; Bolderdijk, J.W.; Keizer, K.; Perlaviciute, G. An integrated framework for encouraging pro-environmental behavior: The role of values, situational factors and goals. J. Environ. Psychol. 2014, 38, 104-115. [CrossRef]

47. Burja, C. Factors Influencing the Companies' Profitability. Ann. Univ. Apulensis Ser. Oeconomica 2011, 2, 1-3. [CrossRef]

48. Sufian, F. Profitability of the Korean banking sector: Panel evidence on bank-specific and macroeconomic determinants. J. Econ. Manag. 2011, 7, 43-72.

49. Kumar, V.; Thrikawala, S.; Acharya, S. Financial inclusion and bank profitability: Evidence from a developed market. Global Financ. J. 2021, 100609. [CrossRef]

50. Kim, M.K.; Eom, J.G. A Study on Determinants of Banks' Profitability: Focusing on the Comparison between before and after Global Financial Crisis. Int. J. Contents. 2018, 18, 196-209.

51. Hoang, V.H.; Hoang, N.T.; Yarram, S.R. Efficiency and shareholder value in Australian banking. Econ. Rec. 2020, 96, 40-64. [CrossRef]

52. Ali, M.; Puah, C.H. The internal determinants of bank profitability and stability. Manag. Res. Rev. 2019, 42, 49-67. [CrossRef]

53. Xu, M.T.; Hu, K.; Das, M.U.S. Bank Profitability and Financial Stability; International Monetary Fund: Washington, DC, USA, 2019.

54. Demirgüç-Kunt, A.; Levine, R. (Eds.) Financial Structure and Economic Growth: A Cross-Country Comparison of Banks, Markets, and Development; MIT Press: Cambridge, MA, USA, 2004. 
55. Ehigiamusoe, K.U.; Guptan, V.; Lean, H.H. Impact of financial structure on environmental quality: Evidence from panel and disaggregated data. Energy Sources Part B Econ. Plan. Policy 2019, 14, 359-383. [CrossRef]

56. Um, T.; Kim, T.; Chung, N. How does an Intelligence Chatbot Affect Customers Compared with Self-Service Technology for Sustainable Services? Sustainability 2020, 12, 5119. [CrossRef]

57. Erkut, B. From digital government to digital governance: Are we there yet? Sustainability 2020, 12, 860. [CrossRef]

58. Toader, D.C.; Boca, G.; Toader, R.; Măcelaru, M.; Toader, C.; Ighian, D.; Rădulescu, A.T. The effect of social presence and chatbot errors on trust. Sustainability 2020, 12, 256. [CrossRef] 